\title{
Changing molecular profile of brain metastases compared with matched breast primary cancers and impact on clinical outcomes
}

\author{
A H Thomson*,1, J McGrane ${ }^{1}$, J Mathew ${ }^{1}$, J Palmer ${ }^{1}$, D A Hilton ${ }^{2}$, G Purvis ${ }^{1}$ and R Jenkins ${ }^{1}$ \\ ${ }^{1}$ Sunrise Centre, Royal Cornwall Hospital, Truro, Cornwall, TR1 3LJ, UK and 'Derriford Hospital, Derriford Road, Crownhill, \\ Plymouth, Devon, PL6 8DH, UK
}

Background: Breast cancer commonly metastasises to the brain, but little is known about changes in the molecular profile of the brain secondaries and impact on clinical outcomes.

Methods: Patients with samples from brain metastases and matched breast cancers were included. Immunohistochemical analysis for oestrogen receptor, progesterone receptor, p27kip1, cyclin D1, epidermal growth factor receptor, insulin like growth factor 1, insulin like growth factor 1 receptor, vascular endothelial growth factor $A$, transforming growth factor- $\beta$ and HER2 receptor was performed. Borderline HER2 results were analysed by fluorescent in situ hybridisation. Levels of expression were compared, with review of effect on clinical outcomes.

Results: A total of 41 patients were included. Of the patients, $20 \%$ had a change in oestrogen receptor or HER2 in their brain metastasis that could affect therapeutic decisions. There were statistically significant rises in brain metastases for p27kip1 $(P=0.023)$ and cyclin D1 $(P=0.030)$ and a fall in vascular endothelial growth factor $\mathrm{A}(P=0.012)$. Overall survival from the time of metastasis increased significantly with oestrogen receptor-positive $(P=0.005)$ and progesterone receptor-positive $(P=0.013)$ brain lesions and with a longer duration from diagnosis of the breast primary $(P<0.001)$.

Conclusions: In this cohort there were phenotypic differences in metastatic brain tumours compared with matched primary breast tumours. These could be relevant for aetiology, and have an impact on prognostication, current and future therapies.

The presence of brain metastases occurring in breast cancer patients is relatively common, noted in $30 \%$ of patients in autopsy studies (Tsukada et al, 1983) and being clinically apparent in up to $16 \%$ of metastatic breast cancer patients (Barnholtz-Sloan et al, 2004). This, along with limited treatment options, can cause significant morbidity and result in a dismal prognosis.

Previous studies have demonstrated certain characteristics of primary breast cancers that make the development of brain metastases more likely, such as being diagnosed at a young age, breast tumours being hormone receptor negative, $>2 \mathrm{~cm}$ in diameter, node positive, grade 3 and HER2 positive (Kennecke et al, 2010; Aversa et al, 2014; Soni et al, 2015). In spite of the development of HER2-targeted therapies such as trastuzumab, HER2-positive metastatic breast cancer patients continue to have a high incidence of brain metastases (25-37\%) because of improving extracranial control of disease, inability of treatments to access or be active in the central nervous system (CNS) or a natural predilection for such tumours to deposit in the CNS (Brufsky et al, 2011; Shen et al, 2015). Increasing use of and improvements in adjuvant cytotoxic chemotherapy also appear to be altering the pattern of metastatic relapse, with fewer relapses overall but a relative increase in non-bone metastases (Yerushalmi et al, 2010). It would therefore appear that

*Correspondence: Dr AH Thomson; E-mail: alastairthomson1@nhs.net

Received 1 October 2015; revised 12 January 2016; accepted 22 January 2016; published online 23 February 2016

(C) 2016 Cancer Research UK. All rights reserved 0007-0920/16 
brain metastases from breast cancer will continue to be a significant clinical problem for some time to come.

The degree to which a biopsy to confirm metastatic disease is required is debated (Amir and Clemons, 2009). However, it is becoming increasingly recognised that there are molecular changes to extracranial breast cancer metastases that could make a difference to treatment, such as the metastatic tumours having a change of HER 2 positivity $24 \%-48 \%$ of the time and a $7-13 \%$ fall in oestrogen receptor (ER)- or progesterone receptor (PR)-positive metastatic tumours (Regitnig et al, 2004; Nishimura et al, 2011; Niikura et al, 2012). Prospective analysis of primary and recurrent breast cancer confirmed changes in ER (10\%), PR (25\%) and HER2 (3\%) (Thompson et al, 2010). However, very little is known about brain metastases and whether they differ at a molecular level to the breast primary and therefore whether an alternative treatment strategy may be indicated.

Published studies that have analysed the molecular profile of breast cancer brain metastases have had small numbers and shown mixed results, tested a limited panel of targets or had variable clinical outcome information. In matched breast and brain sample studies, results have shown development of HER2 amplification in 2 out of 23 cases tested in brain metastases and an excess of epidermal growth factor receptor (EGFR) in the brain metastases (41\% vs 16\%) (Gaedcke et al, 2007). In a study with 43 patients, there was no significant change in ER, PR or HER2 in tissue from the breast and secondary brain malignancy (Johnson et al, 2008), whereas a change was demonstrated in brain metastases for ER, PR or HER2 in 7 out of 24 patients (Yonemori et al, 2008). Testing HER2 alone in 75 matched patient samples, there was a significant rise in brain metastases compared with the breast primary (Duchnowska et al, 2015). Contrary to this, in sample studies of 24 and 21 matched patients, there was a less significant change in HER2, but an apparent loss of ER/PR positivity in brain metastases (Bachmann et al, 2013a, b). This pattern of loss of hormone receptors but a more stable HER2 pattern in CNS tissue was also demonstrated in a study with 120 patients (Duchnowska et al, 2012).

The small size of many of these studies limits statistical power and they have demonstrated contrasting results. There is also developing research and clinical interest in growth pathways beyond ER, PR and HER2 and mechanisms of resistance to current treatments. The fact that CNS metastases are so difficult to access for histology gives an opportunity to add evidence through analysis of the changing patterns of traditional targets in breast primaries and their corresponding brain metastases. Furthermore, their poor prognosis gives impetus to investigate alternative pathways for which there is a paucity of data that could be aberrant and demonstrate further loss of stability of the original breast cancer. If there are significant changes, these may aid prognostication or targeting of drug development and treatment.

There have been huge developments in the understanding of the complexity of breast cancer. Genomic study has recognised aberrant genes that can be useful in predicting prognosis, such as the Oncotype DX 21 gene score (Paik et al, 2004) or in combination with clinical factors in the Endopredict score (Filipits et al, 2011). The identification of specific genomic alterations has enabled grouping of breast cancer into the different intrinsic subtypes of luminal A, luminal B, HER2, basal and normal (Parker et al, 2009) with their varying clinical characteristics and prognoses that can aid therapy decisions.

Within these groupings it is increasingly recognised that there is still much diversity. Multiple drivers for malignancy can occur in a range of cellular control pathways, such as cell cycle regulation, AKT signalling, chromatin function, DNA damage, apoptosis and repair, MAPK signalling, tissue organisation and transcription regulation. The degree of diversity in these breast pathways within breast cancer can be variable and extensive (Yates et al, 2015).
Perhaps because of the difficulty in accessing suitable material for analysis, very little is known about the genomics of breast cancer brain metastases. Salhia et al (2014) performed deep genomic profiling of 35 unmatched brain metastases and identified multiple chromosomal gains and deletions, amplified and deleted genes, enriched cell cycle pathways and defects in cell migration, adhesion and permeability. There is concern that this novel biology is not thoroughly understood, may not be targetable and is heterogeneous with the prospect of molecular evolution and resistance (Tabchy et al, 2013). With these multiple abnormalities, the challenge is to establish the clinically valuable mutations that drive carcinogenesis and metastasis and separate from the bystander background mutations (Goncalves et al, 2014).

Because of this uncertainty regarding the primacy of the multiple genetic abnormalities and their potential clinical utility, we selected for analysis factors that are established therapeutic targets, had clinical data with links to a poor prognosis or putative roles in metastasis development or therapy resistance.

Oestrogen receptor, PR and HER2 were selected to be analysed as they are current prognostic and therapeutic targets. The p27kip1 is a negative regulator of cell proliferation, with upregulation inhibiting the invasion of breast cancer cells (Mizuma et al, 2008). It can affect hormone receptor levels and sensitivity, with low nuclear expression in ER-negative PR-negative small breast cancers (Mirchandani et al, 2011), but upregulation causing antioestrogen insensitivity (Yuan et al, 2007). It may also affect chemosensitivity, with reduced expression of p27kip1 being associated with poor outcomes with CMF chemotherapy (Han et al, 1999) and with links to trastuzumab resistance (Nahta et al, 2004). Conversely, in nodenegative cases, high expression detected by immunohistochemistry indicated a poor prognosis (Barbareschi et al, 2000) but subsequent meta-analysis indicated reduced p27kip1 as an independent prognostic factor for poor overall survival (Guan et al, 2010).

Cyclin D1 is a protein that regulates cell cycle progression during the G1/S-phase transition and when overexpressed can reduce mean generation time of human mammary epithelial cells, contributing to their malignant potential (Kamalati et al, 1998). It appears to promote cell migration as a collaborative oncogene with p27kip1 (Li et al, 2006). Overexpression of cyclin D1 as expressed by immunohistochemistry has been associated with early relapse and poor prognosis, particularly for ER-positive breast cancers (Xu et al, 2013), but with relatively longer survival once metastases have developed (Chung et al, 2014). An association with favourable prognostic factors in breast cancer has been noted (El-Hafez et al, 2012).

Epidermal growth factor receptor is a transmembrane receptor for members of the epidermal growth factor family, triggering cell proliferation. High EGFR has been associated with a poor prognosis in breast cancer ( $\mathrm{Li}$ et al, 2015) and linked to the development of breast cancer brain metastasis (Hohensee et al, 2013), with roles in cell migration and invasion promoting brain metastasis (Nie et al, 2012). EGFR positive breast cancer appears more commonly in patients with poorer prognosis grade 3 disease and oestrogen receptor negative tumours (Stebbing et al, 2011). Increased signalling of EGFR has also been associated with trastuzumab resistance (Gallardo et al, 2012).

Insulin-like growth factor 1 (IGF1) binding to insulin-like growth factor 1 receptor (IGF1R) triggers a signalling cascade that leads to cellular proliferation and antiapoptosis, indicating a potentially significant role in breast cancer progression and metastasis (Margillo et al, 2013; Christopoulos et al, 2015). Chang et al (2013) discovered significantly higher levels of IGF1R in breast cancer stem cells compared with non-breast cancer stem cells and proposed it as an attractive target for therapy. Indeed, when IGF1R was suppressed, growth of breast cancer cells and metastasis was reduced (Xu et al, 2015). Furthermore, in a cell line with a tendency to brain metastasis, high levels of IGF1R were detected (Nishizuka et al, 2002) and, when suppressed, IGF1R 
inhibition attenuates the development of breast cancer brain metastasis (Saldana et al, 2013). Both IGF1 and IGF1R appear to have a role in prognosis (Bahhnassy et al, 2015) and evidence also suggests a role for IGF1R in trastuzumab resistance (Gallardo et al, 2012) and IGF1 in resistance to tamoxifen (Chong et al, 2011).

Vascular endothelial growth factor A (VEGFA) binds to vascular endothelial growth factor receptor 2 (VEGFR2) that appears to mediate many of the known responses to VEGF including angiogenesis, increased vascular permeability, cell migration, invasion and inhibition of apoptosis (Mohammed et al, 2007; Perrot-Applanat and Di Benedetto, 2012). In breast cancer, VEGFA expression as measured by immunohistochemistry (Sun et al, 2014) was significantly higher in primary $v s$ metastatic breast cancer, with higher levels also being associated with low cell proliferation (Manchio et al, 2014). Vascular endothelial growth factor A expression has however been implicated in promoting growth of breast cancer metastases (Kim et al, 2004). When VEGFR2 is inhibited, angiogenesis and tumour growth is also inhibited (Yao et al, 2015) and it is associated with a worse outcome in breast cancer (Ghosh et al, 2008). In terms of impact on therapy, high levels of VEGFA are associated with greater treatment effect for chemotherapy with bevacizumab (Miles et al, 2013), but conversely may reduce tamoxifen (Qu et al, 2008) and radiotherapy efficacy (Manders et al, 2003). One possible explanation for the high incidence of brain metastases in HER2-positive breast cancer is resistance to HER2-targeted therapies in the brain and there are early data that VEGFR2 blockade may overcome this resistance (Kodack et al, 2012).

Transforming growth factor- $\beta$ (TGF $\beta$ ) regulates cell proliferation, differentiation, migration and apoptosis (Imamura et al, 2012). It promotes metastasis in cancer cells (Parvani et al, 2013) and when blocked it appears to inhibit breast cancer cell invasiveness (Wang et al, 2014). It has potential roles in prognosis, being associated with more aggressive tumours likely to metastasise and reduced survival (Bahhnassy et al, 2015), with trastuzumab resistance (Bai et al, 2014) and failure through tamoxifen (Terner et al, 2004). Bahhnassy et al (2015) commented on the promising candidacy of TGF $\beta$ for targeted therapy, along with IGF1/IGF1R and VEGFA.

\section{AIMS AND OBJECTIVES}

The aim of this study was to measure ER, PR, HER2 expression, IGF1 and IGF1R, VEGFA, VEGFR2, EGFR, TGF $\beta$, p27kip1 and cyclin D1 in the primary breast tumour and recurrent tumour in the brain metastasis to quantify the percentage of tumours that have changed their status. The impact of any changes on survival of the patients was also investigated.

\section{MATERIALS AND METHODS}

Patients with resected brain metastases from 1990 to 2011 were identified from a regional electronic database and multidisciplinary team (MDT) meeting records. Clinical data were collected from hospital notes and information gathered on age, number of brain metastases, disease-free interval and overall survival and primary tumour characteristics including size, grade, nodal status and treatments received.

Patients were deemed eligible if histological samples were available from primary invasive carcinoma of the breast and resected (or biopsies from) brain metastases of the same histological type. They were excluded if there was insufficient tissue available from either the breast or the brain malignant process.

Immunohistochemistry (IHC) with tissue microarray analyses and fluorescence in situ hybridisation (FISH) were performed on formalin-fixed paraffin-embedded archive tissue from primary breast tumours and matched brain metastases from the same patients. Anonymised histological and IHC evaluation was performed by a consultant pathologist using a multi-headed light microscope (Olympus BX51, Tokyo, Japan). Three cores for each tumour were evaluated, the scores were tabulated and an average result calculated.

The expression levels of the relevant biomarkers were determined using a subjective composite score based on the evaluation of intensity and percentage of cells exhibiting nuclear or nuclear and/or cytoplasmic staining. An Allred score of $\geqslant 3$ was determined to be positive for ER and PR, with $3+$ HER2 scored positive. Specimens that were reported to have a $2+$ borderline result for HER2 were subsequently analysed for overexpression using FISH. A score of $\geqslant 3$ was also deemed positive for IGF1, IGF1R, VEGFA, VEGFR2, EGFR, TGF $\beta$, p27kip1 and cyclin D1, but as there is less consistent information regarding levels of staining deemed to be positive or negative for non-ER, -PR and HER2 molecules and their corresponding clinical relevance, any degree of change was also reviewed.

Statistical analysis was performed using SPSS Version 19 for Windows software (Statistical Package for the Social Sciences, SPSS Inc., Chicago, IL, USA). Categorical and continuous variables were described using mean (s.d.), median (IQR) or counts (\%) as appropriate. The Kaplan-Meier method was used for survival analysis. Levels of expression in the breast primary and resected brain metastases from each patient were analysed using paired/independent $t$-tests or the nonparametric equivalent Pearson's correlation (two tailed) test to analyse the relationship of survival outcomes and time to brain metastases. Impact of a positive score for the biomarkers on the time from brain metastasis to death was reviewed with the Mann-Whitney test. Statistical significance was accepted if $P<0.05$.

Ethical approval was given by South West 1 Research Ethics Committee of the National Research Ethics Service, REC reference 10/H0203/30.

\section{RESULTS}

A total of 41 patients were identified and eligible for the study. The mean (s.d.) age of the patients was 50.7 (12.4) years, with a median (IQR) 26 (25)-month interval between breast cancer diagnosis and development of brain metastases. The range of time from breast cancer diagnosis to brain metastasis varied considerably, with one patient presenting with CNS metastases with an occult breast primary, whereas the longest duration was 244 months after the original breast diagnosis. Median (IQR) time from brain metastasis diagnosis to death was 15 (23) months, with the median times for survival from the diagnosis of brain metastases in relation to the tested molecules displayed in Table 1 . There was a $>12$-month superior survival relative to the contrary tumour readings if the brain lesion was positive for ER or PR and if negative for IGF1R.

A total of 13 patients (32\%) had a HER2-positive breast primary, with 12 receiving HER2-directed therapy before development of brain metastases. At initial diagnosis, 15 patients (37\%) had an ERpositive breast cancer. A total of 11 patients underwent biopsy of their brain secondary, 30 more extensive surgical resection, with median survival 7 months for the biopsied group and 16 months for the resected. In all, 28 patients received whole-brain radiotherapy (WBRT), 1 patient stereotactic radiotherapy (SRT) alone, 6 patients both WBRT and SRT and 6 did not have radiotherapy information available. In the irradiated group, those receiving stereotactic radiotherapy with or without WBRT had superior outcomes, with median survival 43 months as opposed to 11 months. The clinical details and outcomes are described further in Table 2.

Overall, there were only 3 patients (7\%) who had no change in comparing the breast primary and brain secondary from positive to 
negative or negative to positive for at least one of the tested molecules. An example of a change in the characteristic tested is seen in Figure 1.

Table 1. Median overall survival from brain metastasis diagnosis in relation to presence or absence of tested molecule in the brain lesion

\begin{tabular}{|l|c|c|}
\hline Molecule & $\begin{array}{c}\text { Positive (+) or } \\
\text { negative (-) }\end{array}$ & $\begin{array}{c}\text { Median overall survival } \\
\text { (months) }\end{array}$ \\
\hline ER & + & 22 \\
& - & 6 \\
\hline \multirow{2}{*}{ PR } & + & 36 \\
\multirow{2}{*}{ HER2 } & - & 11 \\
\hline \multirow{2}{*}{ EGFR } & - & 17 \\
& + & 10 \\
\hline \multirow{2}{*}{ IGF1 } & - & 18 \\
& + & 17.5 \\
\hline \multirow{2}{*}{ IGF1R } & - & 13.5 \\
& + & 23 \\
\hline \multirow{2}{*}{ TGF $\beta$} & - & 7.5 \\
& - & 26 \\
\hline \multirow{2}{*}{ P27kip1 } & + & 13.5 \\
\hline \multirow{2}{*}{ Cyclin D1 } & - & 23 \\
\hline \multirow{2}{*}{ VEGFA } & - & 9 \\
\hline \multirow{2}{*}{ VEGFR2 } & + & 17 \\
& - & NA \\
\hline
\end{tabular}

Abbreviations: EGFR = epidermal growth factor receptor; $\mathrm{ER}=$ oestrogen receptor; $\mid \mathrm{GF} 1=$ insulin-like growth factor 1; IGF1R=insulin-like growth factor 1 receptor; NA= not applicable; $\mathrm{PR}=$ progesterone receptor; TGF $\beta=$ transforming growth factor $-\beta$; VEGFA=vascular endothelial growth factor A; VEGFR2 = vascular endothelial growth factor receptor 2.
Specific levels of positive findings in the breast primary and brain secondary with changes in the molecular profile of the breast lesion compared with the brain secondary are illustrated in Table 3.

There was a change in $>10 \%$ of the 41 patients from a positive breast primary to a negative brain secondary for p27kip 1 and from a negative breast cancer to a positive brain metastasis for HER2, EGFR, IGF1, cyclin D1 and p27kip1. When considering the proportion of tumours that changed where four or more were initially positive or negative, it is notable that over half with an originally negative breast cancer turned positive in their brain metastases for IGF1, IGF1R, p27kip1 and cyclin D1.

There were statistically significant rises in the brain metastases for p27kip1 $(P=0.023)$ and cyclin D1 $(P=0.030)$. Within the brain metastases, VEGFA demonstrated a significant fall in levels $(P=0.012)$, although when considering a level of 3 for staining as positive, there was no change between the breast primary and brain secondary, and degree of change for VEGFA was small, with no breast or brain samples scoring over 2 on immunohistochemistry. Analysis of these alterations from 'negative' in the breast to 'positive' or vice versa in the brain sample and their influence on prognosis demonstrated that they did not have a significant impact on the time from brain metastasis to death. There was also no
A

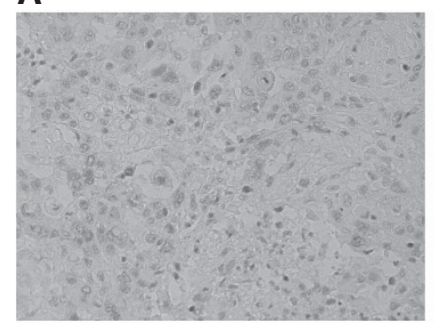

B

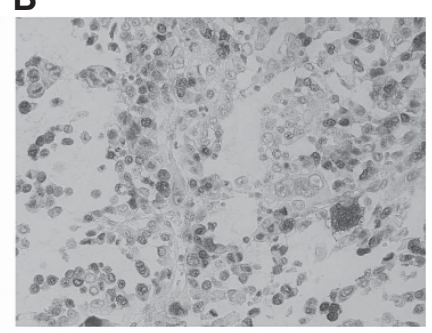

Figure 1. (A) Photomicrograph of low expression of p27kip1 in a primary breast tumour. IHC $\times 20$. (B) Photomicrograph of high expression of p27kip1 in a brain metastasis. $I H C \times 20$.

Table 2. Treatment received by patients before and after brain metastasis and impact on times to progression and survival

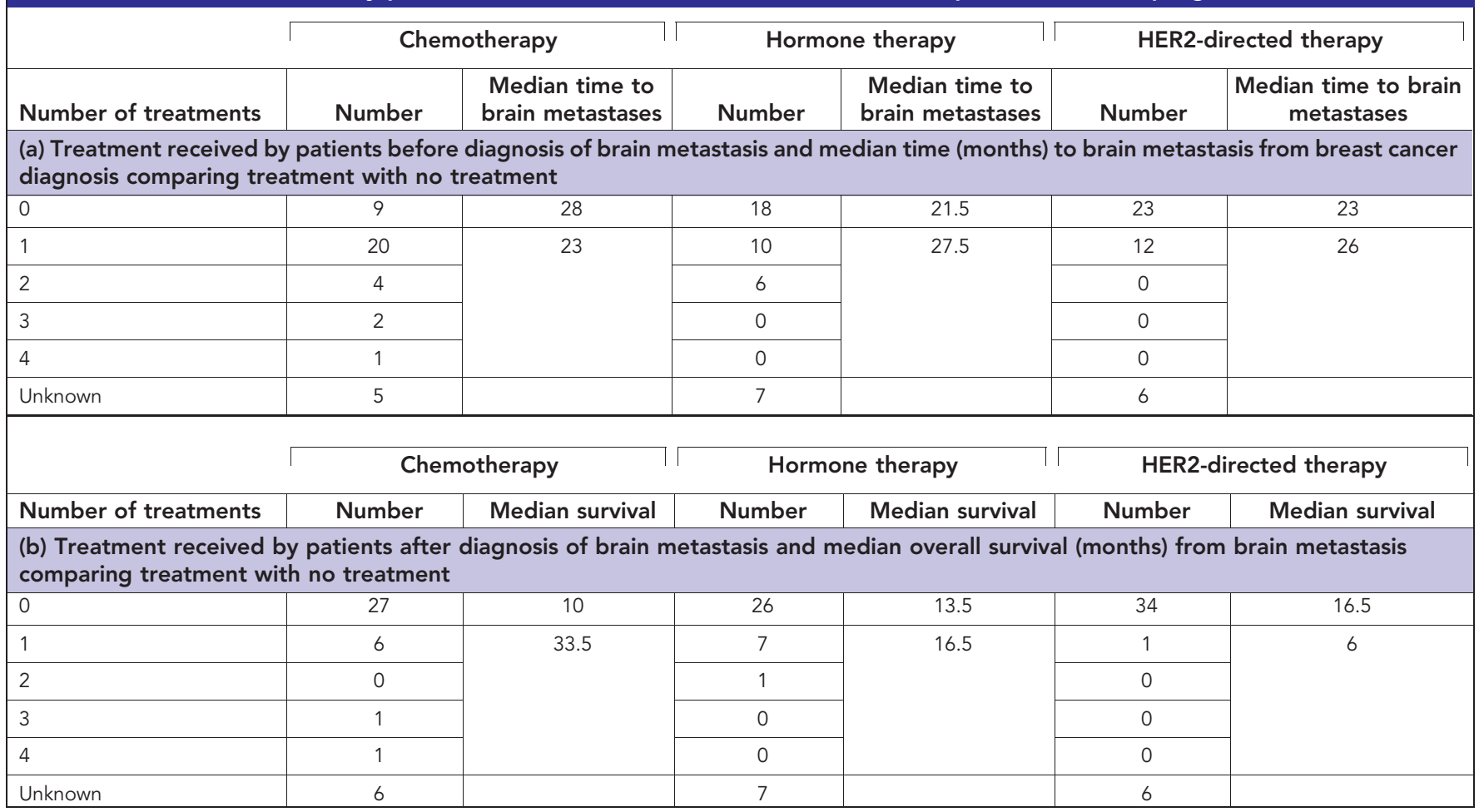


Table 3. Number and percentage of patients with positive breast cancer and brain metastasis for the molecule tested and changes in profile from breast primary to brain metastasis

\begin{tabular}{|c|c|c|c|c|c|c|}
\hline \multirow{2}{*}{$\begin{array}{l}\text { Molecule } \\
\text { ER }\end{array}$} & \multirow{2}{*}{$\begin{array}{c}\begin{array}{c}\text { Number and } \% \text { of breast } \\
\text { tumours positive }\end{array} \\
15(37 \%)\end{array}$} & \multirow{2}{*}{$\begin{array}{c}\text { Number and } \% \text { of brain } \\
\text { metastases positive }\end{array}$} & \multicolumn{2}{|c|}{$\begin{array}{c}\text { Number of breast positive to } \\
\text { brain negative ( } \% \text { of breast } \\
\text { positives changing) }\end{array}$} & \multicolumn{2}{|c|}{$\begin{array}{c}\text { Number of breast negative to } \\
\text { brain positive ( } \% \text { of breast } \\
\text { negatives changing) }\end{array}$} \\
\hline & & & 0 & $(0 \%)$ & 3 & $(12 \%)$ \\
\hline PR & $6(15 \%)$ & $7(17 \%)$ & 0 & (0\%) & 1 & (3\%) \\
\hline HER2 & 13 (32\%) & 17 (41\%) & 1 & $(8 \%)$ & 5 & $(18 \%)$ \\
\hline EGFR & 24 (59\%) & 29 (71\%) & 1 & $(4 \%)$ & 6 & $(35 \%)$ \\
\hline IGF1 & 29 (71\%) & 38 (93\%) & 3 & $(10 \%)$ & 12 & $(100 \%)$ \\
\hline IGF1R & 37 (90\%) & 38 (93\%) & 3 & (8\%) & 4 & $(100 \%)$ \\
\hline TGF $\beta$ & 40 (98\%) & 40 (98\%) & 1 & (3\%) & 1 & $(100 \%)$ \\
\hline P27kip1 & 21 (51\%) & 31 (76\%) & 5 & $(24 \%)$ & 15 & (75\%) \\
\hline Cyclin D1 & $18(44 \%)$ & 27 (66\%) & 3 & $(17 \%)$ & 12 & (52\%) \\
\hline VEGFA & $0(0 \%)$ & $0(0 \%)$ & 0 & $(0 \%)$ & 0 & $(0 \%)$ \\
\hline VEGFR2 & 40 (98\%) & 40 (98\%) & 1 & (3\%) & 1 & $(100 \%)$ \\
\hline
\end{tabular}

Abbreviations: EGFR=epidermal growth factor receptor; ER=oestrogen receptor; IGF1=insulin-like growth factor 1; IGF1R=insulin-like growth factor 1 receptor; NA= not applicable; $\mathrm{PR}=$ progesterone receptor; TGF $\beta=$ transforming growth factor $\beta$; VEGFA=vascular endothelial growth factor $\mathrm{A}$; VEGFR2=vascular endothelial growth factor receptor 2 .

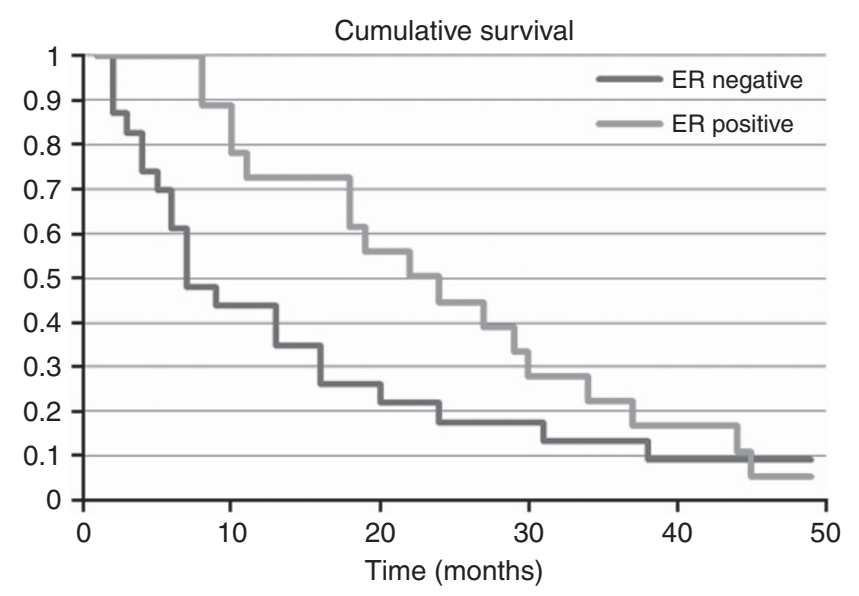

Figure 2. Kaplan-Meier curve illustrating survival times from the diagnosis of brain metastases according to ER status of the brain secondary.

statistically significant influence on survival duration from brain metastasis for clinical factors, such as extent of surgery or radiotherapy.

When analysing the individual characteristics of the brain metastasis and impact on survival from their diagnosis, there was a significant improvement in outcome if the brain lesion was ER positive $(P=0.005)$, as displayed in Figure 2 , or $\mathrm{PR}$ positive $(P=0.013)$, but not for HER2-positive lesions $(P=0.100)$. In contrast, breast primaries that were ER positive in this group had a trend that was not statistically significant $(P=0.059)$ towards an improved overall prognosis. Survival was however significantly improved if there was a longer time from primary diagnosis to the development of brain secondaries $(P<0.001)$.

\section{DISCUSSION}

The patients in this study seem to be a reasonably representative cohort in this clinical setting. In a study of breast cancer patients undergoing craniotomy for metastases (Leone et al, 2015), median survival times from brain metastases were identical at 15 months. Initial tumour biology was similar with ER-positive breast tumours in $40 \%$ vs $37 \%$ in this study and HER2 positivity in $45 \%$ compared with $32 \%$ respectively.

This and other studies have demonstrated changes in the CNS metastases of breast cancer patients. Possible technical explanations for this include simply a natural discordance in assays between the two sets of samples tested. However, at least for the case of ER, there is evidence that multiple simultaneous assays have a low discordant rate of only 3\% (Hull et al, 1983). Another possible explanation of variation due to technical reasons is tumour heterogeneity. In this study, by taking three random cores and calculating the mean, the impact of these will be reduced. It was also notable that there was a trend for more positive results in the brain metastases compared with the breast primary for the majority of molecules tested. If there was an element of denaturation of the molecule being tested in the older breast specimens producing a false negative reading, then this trend could result. However, there were high levels of positive levels in the original breast tumour, and with a median time of only 26 months between sampling of the breast and brain tumours, this would seem unlikely to affect the results significantly, even if this was a real phenomenon. Furthermore, there were a number of cases where the opposite occurred, with the brain lesion losing positivity, implying that there is a real change between the primary and secondary tumour. Prospective testing would be required to circumvent this issue fully.

The results of this study suggest that brain metastases are phenotypically very different, and therefore quite possibly biologically different to the breast primary. In many cases, factors linked to drug resistance, metastases or poor prognosis became more evident. Possible explanations for these changes include mutations developing in the original cancer cell or, alternatively, with an original heterogeneous tumour, oncological therapies serving to select out cells with a different, more therapy-resistant biology.

Statistically significant increases in the brain secondaries were seen for p27kip1 and cyclin D1. In the case of p27kip1, downregulation has generally been associated with poorer outcomes, in which case elevated levels in CNS disease might be unexpected. However, one area that raised levels seems to have a detrimental impact is by causing antioestrogen resistance (Yuan et $a l, 2007)$ that could consequently lead to increased risk of recurrence and metastasis. Cyclin D1 has been linked with a poorer prognosis and can act in collaboration with p27kip1, promoting cell migration (Li et al, 2006). The fact that both are elevated in this 
study hints at a possible combination effect in the establishment of CNS metastases. The other significant change in the brain metastases was a reduction in VEGFA. Previous studies have noted a reduction in VEGFA at other sites of metastatic disease (Sun et al, 2014) and an association with a more proliferative nature (Manchio et al, 2014), in keeping with the findings of this study.

For current National Institute for Health and Care Excellence (NICE)-approved treatments and their targets, 8 patients had a change to either ER or HER2 (20\% of the group) that could have made a difference to their treatment. The question arises as to how much the metastases that have changed to a positive level would benefit from appropriate ER- or HER2-directed therapy. Although this is not clear in this patient group, there is emerging evidence that, overall, HER2-positive brain metastases have superior outcomes with use of HER2-targeted therapy (Hayashi et al, 2015). The most significant difference for this group in terms of survival time post brain metastasis comparing no treatment with an individual treatment is for chemotherapy and stereotactic brain radiotherapy favouring more intensive treatment. However, there are a multitude of cofounders with potential to affect this, including patient choice, performance status and comorbidities as well as tumour extent and biology.

Previous studies have suggested in general a fall in the hormone sensitivity of breast cancer metastases, including brain metastases (Duchnowska et al, 2012; Bachmann et al, 2013a, b). This was not the case in this group of patients, with three brain tumours developing ER positivity. Knowing the hormone receptor levels in the brain metastasis appears to give a good indication as to prognosis that in this cohort was stronger statistically than the impact on prognosis with an ER-positive breast cancer. Where they are positive, therapies targeting the hormone pathway become an option. It would therefore seem appropriate to reanalyse tissue obtained from biopsy or resection of a brain metastasis for ER, PR and HER2, with information gathered from this potentially influencing treatment options and guiding prognosis estimation.

In this study, p27kip1, cyclin D1 and VEGFA were significantly altered in brain metastases, with high proportions of brain secondaries developing positivity for p27kip1, cyclin D1, IGF1 and IGF1R. This raises interesting questions into the degree of change and diversity of CNS breast cancer metastases that, in turn, hints at mechanisms for development of such secondaries and possible therapeutic targets. It is however early information in a subset of breast cancer patients who have had little past molecular analysis, and hence there is not a substantial amount of evidence to add to these findings. Regarding impact on clinical outcomes, the changes in p27kip1, cyclinD1 and VEGFA did not have a definite influence on overall prognosis. However, the number of patients in this study means that a moderate effect on clinical outcomes cannot be excluded. Future research could gather more evidence in these areas and eventually trigger development of improved therapies capable of traversing the blood-brain barrier and of activity in the unique microenvironment of the CNS for this poor prognostic group. It would seem appropriate on the basis of results of this study to include investigation of p27kip1, cyclin D1, VEGFA, IGF1 and IGF1R in future work.

\section{CONCLUSIONS}

In this cohort there were demonstrable phenotypic differences between primary breast cancers and their corresponding brain metastases. In particular, the expression levels of p27kip1 and cyclin D1 were significantly raised in brain metastases, with VEGFA reduced. In addition, EGFR, IGF1 and IGF1R were relatively frequently altered, with the majority becoming positive in the brain metastasis. These changes however did not affect survival time from the diagnosis of the brain secondary.
In all, $20 \%$ of patients had a change in ER or HER2 in their brain metastasis that could affect therapeutic decisions. It would seem prudent, therefore, to undertake analysis for these clinical targets if tissue is available from a brain secondary. Patients with a long time from original diagnosis to development of brain metastases and with hormone receptor-positive intracranial lesions had the best outcome. Nevertheless, prognosis is still poor, and much work needs to be done to gain a better understanding of the nature of breast cancer brain metastases to improve therapy and outcomes.

\section{ACKNOWLEDGEMENTS}

Funding for the study was obtained through the Miracle Trust Charity. They provided financial support, with no influence on the design, analysis or writing of the study.

\section{CONFLICT OF INTEREST}

The authors declare no conflict of interest.

\section{REFERENCES}

Amir E, Clemons M (2009) Should a biopsy be recommended to confirm metastatic disease in women with breast cancer? Lancet Oncol 10(10): 933.

Aversa C, Rossi V, Geuna E, Martinello R, Milani A, Redana S, Valabrega G, Aglietta M, Montemurro F (2014) Metastatic breast cancer subtypes and central nervous system metastases. Breast 23(5): 623-628.

Bachmann C, Grischke EM, Staebler A, Schittenhelm J, Wallwiener D (2013a) CNS metastases of breast cancer show discordant immunohistochemical phenotype compared to primary. J Cancer Res Clin Oncol 139(4): 551-556.

Bachmann C, Grischke EM, Staebler A, Schittenhelm J, Wallwiener D (2013b) Receptor change-clinicopatholologic analysis of matched pairs of primary and cerebral metastatic breast cancer. J Cancer Res Clin Oncol 139(11): 1909-1916.

Bahhnassy A, Mohanad M, Shaarawy S, Ismail MF, El-Bastawisy A, Ashwmawy AM, Zekri AR (2015) Transforming growth factor- $\beta$, insulin-like growth factor 1 /insulin-like growth factor 1 receptor and vascular endothelial growth factor-A: prognostic and predictive markers in triple-negative and non-triple-negative breast cancer. Mol Med Rep 12(1): 851-864.

Bai WD, Ye XM, Zhang MY, Zhu HY, Xi WJ, Huang X, Zhao J, Gu B, Zheng GX, Yang AG, Jia LT (2014) MiR-200c suppresses TGF- $\beta$ signalling and counteracts trastuzumab resistance and metastasis by targeting ZNF217 and ZEB1 in breast cancer. Int J Cancer 135(6): 1356-1368.

Barbareschi M, van Tinteren H, Mauri FA, Veronese S, Peterse H, Maisonneuve P, Caffo O, Scaioli H, Doglioni C, Galligioni E, Dalla Palma P, Michalides R (2000) p27(kip1) expression in breast carcinomas: an immunohistochemical study on 512 patients with long term follow up. Int J Cancer 89(3): 236-241.

Barnholtz-Sloan JS, Sloan AE, Davis FG, Vigneau FD, Lai P, Sawaya RE (2004) Incidence proportions of brain metastases in patients diagnosed (1973-2001) in the Metropolitan Detroit Cancer Surveillance System. J Clin Oncol 22(14): 2865.

Brufsky AM, Mayer M, Rugo HS, Kaufman PA, Tan-Chiu E, Tripathy D, Tudor IC, Wang LI, Brammer MG, Shing M, Yood MU, Yardley DA (2011) Central nervous system metastases in patients with HER2-positive metastatic breast cancer: incidence, treatment, and survival in patients from registHER. Clin Cancer Res 17(14): 4834.

Chang WW, Lin RJ, Yu J, Chang WY, Fu CH, Lai A, Yu JC, Yu AL (2013) The expression and significance of IGF1R and its pathway on breast cancer stem/progenitors. Breast Cancer Res 15(3): R39.

Chong K, Subramanian A, Sharm A, Mokbel K (2011) Measuring IGF-1, ER- $\alpha$ and EGFR expression can predict tamoxifen resistance in ER-positive breast cancer. Anticancer Res 31(1): 23-32.

Christopoulos PF, Msaouel P, Koutsilieris M (2015) The role of the insulinlike growth factor-1 system in breast cancer. Mol Cancer 14: 43. 
Chung J, Noh H, Park KH, Choi E, Han A (2014) Longer survival in patients with breast cancer with cyclin D1 overexpression after tumour recurrence: longer, but occupied with disease. J Breast Cancer 17(1): 47-53.

Duchnowska R, Dziadziusko R, Trojanowski T, Mandat T, Och W, Czartoryska-Arlukowicz, Radecka B, Olszewski W, Szubstarski F, Koslowski W, Jarosz B, Rogowski W, Kowalczyk A, Limon J, Biernat W, Jassem J. Polish Brain Metastasis Consortium (2012) Conversion of epidermal growth factor receptor 2 and hormone receptor expression in breast cancer metastases to the brain. Breast Cancer Res 14(4): R119.

Duchnowska R, Sperinde J, Chenna A, Huang W, Weidler JM, Winslow J, Haddad M, Paquet A, Lie Y, Trojanowski T, Mandat T, Kowalczyk A, Czartoryska-Arlukoxicz B, Radecka B, Jarosz B, Staszkiewicz R, Kalinka-Warzocha E, Chudzik M, Biernat W, Jassem J (2015) Quantitative HER2 and p95HER2 levels in primary breast cancers and matched brain metastases. Neuro Oncol 17: 1241-1249.

El-Hafez AA, El Aaty Shawky A, Hasan B (2012) Cyclin D1 overexpression associates with favourable prognostic factors in invasive breast carcinoma. Cancer Biomark 12(4): 149-154.

Filipits M, Rudas M, Jakesz R, Dubsky P, Fitzal F, Singer CF, Dietze O, Greil R, Jelen A, Sevelda P, Freibauer C, Muller V, Janicke F, Schmidt M, Kolbl H, Rody A, Kaufmann M, Schroth W, Brauch H, Schwab M, Fritz P, Weber WE, Feder IS, Hennig G, Kronnenwett R, Gehrmann M, Gnant M, EP Investigators (2011) A new molecular predictor of distant recurrence in ER-positive, HER2-negative breast cancer adds independent information to conventional clinical risk factors. Clin Cancer Res 17(18): 6012-6020.

Gaedcke J, Traub F, Milde S, Wilkens L, Stan A, Ostertag H, Christgen M, von Wasielewski R, Kreipe HH. (2007) Predominance of the basal type and Her-2/neu type in brain metastasis from breast cancer. Mod Pathol 20(8): 864-870.

Gallardo A, Lerma E, Escuin D, Tibau A, Munoz J, Ojeda B, Barnadas A, Adrover E, Sanchez-Tejada L, Giner D, Ortiz-Martinez F, Peiro G (2012) Increased signalling of EGFR and IGFR1, and deregulation of PTEN/PI3K/Akt pathway are related with trastuzumab resistance in HER2 breast carcinomas. Br J Cancer 106(8): 1367-1373.

Ghosh S, Sullivan CO, Zerkowski MP, Molharo AM, Rimm DL, Camp RL, Chung GG. (2008) High levels of vascular endothelial growth factor (VEGF) and its receptors (VEGFR-1, VEGFR-2, neuropilin-1) are associated with worse outcome in breast cancer. Hum Pathol 39(12): 1835-1843.

Goncalves R, Warner WA, Luo J, Ellis MJ (2014) New concepts in breast cancer genomics and genetics. Breast Cancer Res 16(5): 460.

Guan X, Wang Y, Xie R, Chen L, Bai J, Lu J, Kuo MT (2010) p27(kip1) as prognostic factor in breast cancer: a systematic review and meta-analysis. J Cell Mol Med 14(4): 944-953.

Han S, Park K, Kim HY, Lee MS, Kim HJ, Kim YD (1999) Reduced expression of p27kip1 protein is associated with poor clinical outcome of breast cancer patients treated with systemic chemotherapy and is linked to cell proliferation and differentiation. Breast Cancer Res Treat 55(2): 161-167.

Hayashi N, Niikura N, Masuda N, Takashima S, Nakamura R, Watanabe K, Kanbayashi C, Ishida M, Hozumi Y, Tsuneizumi M, Kondo N, Naito Y, Honda Y, Matsui A, Fujisawa T, Oshitanai R, Yasojima H, Yamauchi H, Saji S, Iwata H (2015) Prognostic factors of HER2-positive breast cancer patients who develop brain metastasis: a multicentre retrospective analysis. Breast Cancer Res Treat 149(1): 277-284.

Hohensee I, Lamszus K, Riethdorf S, Meyer-Staekling S, Glatzel M, Matschke J, Witzel I, Westphal M, Brandt B, Muller V, Pantel K, Wikman H (2013) Frequent genetic alterations in EGFR- and HER2- driven pathways in breast cancer brain metastases. Am J Pathol 183(1): 83-95.

Hull 3rd DF, Clark GM, Osborne CK, Chamness GC, Knight 3rd WA, McGuire WL (1983) Multiple estrogen receptor assays in human breast cancer. Cancer Res 43(1): 413.

Imamura T, Hikita A, Inoue Y (2012) The roles of TGF- $\beta$ signalling in carcinogenesis and breast cancer metastasis. Breast Cancer 19(2): 118-124.

Johnson ML, Nehhozina T, Conlin AK, Hsu M, Patil S, Jhaveri K, Hudis CA, Brogi E, Seidman AD (2008) Clinical and pathologic correlates in breast cancer (BC) brain metastasis (BM)tissue microarray (TMA) studies. J Clin Oncol 26 (May 20 supplement; abstract 1039).

Kamalati T, Davies D, Titley J, Crompton MR (1998) Functional consequences of cyclin D1 overexpression in human mammary luminal epithelial cells. Clin Exp Metastasis 16(5): 415-426.
Kennecke H, Yerushalmi R, Woods R, Cheang MCU, Voduc D, Speers CH, Nielsen TO, Gelmon K (2010) Metastatic behaviour of breast cancer subtypes. J Clin Oncol 28(20): 3271-3277.

Kim LS, Huang S, Lu W, Lev DC, Price JE (2004) Vascular endothelial growth factor expression promotes the growth of breast cancer metastases in nude mice. Clin Exp Metastasis 21(2): 107-108.

Kodack DP, Chung E, Yamashita H, Incio J, Duyverman AM, Song Y, Farrar CT, Huang Y, Ager E, Kamoun W, Goel S, Snuderl M, Lussiez A, Hiddingh L, Mahmood S, Tannous BA, Eichler AF, Fukumura D, Engelman JA, Jain RK (2012) Combined targeting of HER2 and VEGFR2 for effective treatment of HER2 amplified breast cancer brain metastases. Proc Natl Acad Sci USA 109(45): E3119-E3127.

Leone JP, Lee AV, Brufsky AM (2015) Prognostic factors and survival of patients with brain metastases from breast cancer who underwent craniotomy. Cancer Med 4(7): 989-994.

Li J, Su W, Zhang S, Hu Y, Liu J, Zhang X, Bai J, Yuan W, Hu L, Cheng T, Zetterberg A, Lei Z, Zhang J. (2015) Epidermal growth factor receptor and AKT1 gene copy numbers by multi-gene fluorescence in situ hybridisation impact on prognosis in breast cancer. Cancer Sci 106(5): 642-649.

Li Z, Jino X, Wang C, Ju X, Lu Y, Yuan L, Lisanti MP, Katiyar S, Restell RG (2006) Cyclin D1 induction of cellular migration requires p27(kip1). Cancer Res 66(20): 9986-9994.

Manchio LB, Madallozo BB, Capellasso BA, Jardim BV, Moschetta MG, Jampetro J, Soares FA, Zuccari DA (2014) Immunohistochemical investigation of the angiogenic proteins VEGF, HIF- $1 \alpha$ and CD34 in invasive ductal carcinoma of the breast. Acta Histochem 116(1): 148-157.

Manders P, Sweep FC, Tjan-Heijnen VC, Guerts-Moespot A, van Tienoven DT, Foekens JA, Span PN, Bussink J, Beex LV (2003) Vascular endothelial growth factor independently predicts the efficacy of postoperative radiotherapy in node-negative breast cancer patients. Clin Cancer Res 9(17): 6363-6370.

Miles DW, de Haas SL, Dirix LY, Romieu G, Chan A, Pivot X, Tomczak P, Provencher L, Cortes J, Delmar PR, Scherer SJ (2013) Biomarker results from the AVADO phase 3 trial of first-line bevacizumab plus docetaxel for HER2-negative metastatic breast cancer. $\mathrm{Br} J$ Cancer 108(5): 1052-1060.

Morgillo F, De Vita F, Antoniol G, Orditura M, Auriemma PP, Diadema MR, Lieto E, Savastano B, Festino L, Laterza MM, Fabozzi A, Ventriglia J, Petrillo A, Gardiello F, Barbarini A, Iovono F (2013) Serum insulin-like growth factor 1 correlates with the risk of nodal metastasis in endocrinepositive breast cancer. Curr Oncol 20(4): e283-e288.

Mirchandani D, Roses DF, Inghirami G, Zeleniuch-Jacquette A, Cangiarella J, Guth A, Safyan RA, Formenti SC, Pagano M, Muggia F (2011) Loss of p27kip1 expression in fully staged node-negative breast cancer: association with lack of hormone receptors in T1a/b, but not T1c infiltrative ductal carcinoma. Anticancer Res 31(12): 4401-4405.

Mizuma M, Katayose Y, Yamamoto K, Shiraso S, Sasaki T, Yabuuchi S, Oda A, Masuda K, Rikiyama T, Onogawa T, Ohtsuka H, Motoi F, Egawa S, Unno M (2008) Up-regulated p27kip1 reduced metalloproteinase- 9 and inhibits invasion of human breast cancer cells. Anticancer Res 28(5A): 2669-2677.

Mohammed RA, Green A, El-Shikh S, Paish EC, Ellis JO, Martin SG (2007) Prognostic significance of vascular endothelial cell growth factors-A, -C and $-\mathrm{D}$ in breast cancer and their relationship with angio- and lymphangiogenesis. Br J Cancer 96(7): 1092-1100.

Nahta R, Takahashi T, Ueno NT, Hung MC, Esteva FJ (2004) P27(kip1) down-regulation is associated with trastuzumab resistance in breast cancer cells. Cancer Res 64(11): 3981-3986.

Nie F, Yang J, Wen S, An YL, Ding J, Ju SH, Zhao Z, Chen HJ, Peng XG, Wong ST, Zhao H, Teng GJ (2012) Involvement of epidermal growth factor receptor overexpression in the promotion of breast cancer brain metastasis. Cancer 118(21): 5198-5209.

Niikura N, Liu J, Hayashi N, Mittendorf EA, Gong Y, Palla SL, Tokuda Y, Gonzalez-Angulo AM, Hortobagyi GN, Ueno NT (2012) Loss of human epidermal growth factor receptor 2 (HER2) expression in metastatic sites of HER2-overexpressing primary breast tumours. J Clin Oncol 30(6): 593-599.

Nishimura R, Osako T, Okumura Y, Tashima R, Toyozumi Y, Arima N (2011) Changes in the ER, PgR, HER2, p53 and Ki-67 biological markers between primary and recurrent breast cancer: discordance rates and prognosis. World J Surg Oncol 9: 131.

Nishizuka I, Ishikawa T, Hamaguchi Y, Kamiyama M, Ichikawa Y, Kadota K, Miki R, Tomaru Y, Mizono Y, Tominaga N, Yano R, Goto H, Nitanda H, Togo S, Okazaki Y, Hayashizaki Y, Shimada H (2002) Analysis of gene 
expression involved in brain metastasis from breast cancer using cDNA microarray. Breast Cancer 9(1): 26-32.

Paik S, Shak S, Tang G, Kim C, Baker J, Cronin M, Baehner FL, Walker MG, Watson D, Park T, Hiller W, Fisher ER, Wickerham DL, Bryant J, Wolmark N (2004) A multigene assay to predict recurrence of tamoxifentreated, node-negative breast cancer. N Engl J Med 351(27): 2817-2826.

Parker JS, Mullins M, Cheang MC, Leung S, Voduc D, Vickery T, Davies S, Fauroni C, He X, Hu Z, Quackenbush JF, Stijleman IJ, Palazzo J, Marron JS, Nobel AB, Mardis E, Nieben TO, Ellis MJ, Perou CM, Bernard PS (2009) Supervised risk predictor of breast cancer based on intrinsic subtypes. J Clin Oncol 27(8): 1160-1167.

Parvani JG, Galliher-Beckley AJ, Schiermann BJ, Schiemann WP (2013) Targeted inactivation of $\beta 1$ integrin induces $\beta 3$ integrin switching, which drives breast cancer metastasis by TGF- $\beta$. Mol Biol Cell 24(21): 3449-3459.

Perrot-Applanat M, Di Benedetto M (2012) Autocrine functions of VEGF in breast tumour cells: adhesion, survival and invasion. Cell Adh Migr 6(6): 547-553.

Qu Z, van Ginkel S, Roy AM, Westbrook L, Nasrin M, Maxwitenko Y, Frost AR, Carey D, Wang W, Li R, Grizzle WE, Thotassery JV, Kern FG (2008) Vascular endothelial growth factor reduces tamoxifen and promotes metastatic colonisation and desmoplasia in breast tumours. Cancer Res 68(15): 6232-6240.

Regitnig P, Schippinger W, Lindbauer M, Samonigg H, Lax SF (2004) Change of HER-2/neu status in a subset of distant metastases from breast carcinomas. J Pathol 203: 918-926.

Saldana SM, Lee HH, Lowery FJ, Khotskaya YB, Xia W, Zhang C, Chang SS, Chou CK, Steeg PS, Yu D, Hung MC (2013) Inhibition of type 1 insulinlike growth factor receptor signalling attenuates the development of breast cancer brain metastases. PLoS One 8(9): e73406.

Salhia B, Kiefer J, Ross JT, Matapally R, Martinez RA, Johnson KN, DiPerna DM, Paquette KM, Jung S, Nasser S, Wallstrom G, Tembe W, Baker A, Carpten J, Resau J, Ryken T, Sibenaller Z, Petricoin EF, Liotta LA, Ramanathan RK, Berens ME, Tran NL (2014) Integrated genomic and epigenomic analysis of breast cancer brain metastasis. PLoS One 9(1): e85448.

Shen Q, Sahin AA, Hess KR, Suki D, Aldape KD, Sawaya R, Ibrahim NK (2015) Breast cancer with brain metastases: clinicopathological features, survival, and paired biomarker analysis. Oncologist 20(5): 466-473.

Soni A, Ren Z, Hameed O, Chanda D, Morgan CJ, Siegal GP, Wei S (2015) Breast cancer subtypes predispose the site of distant metastases. Am J Clin Pathol 143(4): 471-478.

Stebbing J, Thiyagarajan A, Surendrakumar V, Payne R, Krell J, Szydlo R, Preston D, Lewis JS, Coombes RC, Shousa S (2011) EGFR status in early breast cancer is associated with cellular proliferation but not cross-talk. J Clin Pathol 84(9): 829-831.

Sun L, Yu DH, Sun SY, Cao SS, Wei L (2014) Expressions of ER, PR, HER-2, COX-2and VEGF in primary and relapsed/metastatic breast cancers. Cell Biochem Biophys 68(3): 511-516.

Tabchy A, Ma CX, Bose R, Ellis MJ (2013) Incorporating genomics into breast cancer clinical trials and care. Clin Cancer Res 19(23): 6371-6379.
Thompson AM, Jordan LB, Quinlan P, Anderson E, Skene A, Dewar JA, Purdie CA. Breast Recurrence in Tissues Study Group (2010) Prospective comparison of switches in biomarker status between primary and recurrent breast cancer: the Breast Recurrence In Tissues Study (BRITS). Breast Cancer Res 12(6): R92.

Tsukada Y, Fouad A, Pickren JW, Lane WW (1983) Central nervous system metastasis from breast carcinoma. Autopsy study. Cancer 52(12): 2349.

Turner S, Sherratt J, Cameron D (2004) Tamoxifen treatment failure in cancer and the non-linear dynamics of TGF beta. J Theor Biol 229(1): 101-111.

Wang XG, Meng Q, Qi FM, Yang QF (2014) Blocking TGF- $\beta$ inhibits breast cancer cell invasiveness via ERK/S100A4 signal. Eur Rev Med Pharmacol Sci 18(24): 3844-3853.

Xu XL, Chen SZ, Chen W, Zheng WH, Xia XH, Yang HJ, Li B, Mao WM (2013) The impact of cyclin D1 overexpression on the prognosis of ET-positive breast cancers: a meta-analysis. Breast Cancer Res Treat 139(2): 329-339.

Xu YM, Wang HJ, Chen F, Guo WH, Wang YY, Li HY, Tang JH, Ding Y, Shen YC, Li M, Xuan WY, Liu LH, Wang J, Wang XR, Gao ZJ, Liang XB, Su DM (2015) HRD1 suppresses the growth and metastasis of breast cancer cells by promoting IGF-1R degradation. Oncotarget 6(40): 42854-42867.

Yao Y, Jing Y, Chong GP, Yun YL, Ping T, Gui PG, Shao Y (2015) Xanthatin, a novel potent inhibitor of VEGFR2 signalling, inhibits angiogenesis and tumour growth in breast cancer cells. Int J Clin Exp Pathol 8(9): 10355-10364.

Yates LR, Gerstung M, Knappskog S, Desmedt C, Gundem G, Van Loo P, Aas T, Alexandrov LB, Larsimont D, Davies H, Li Y, Ju YS, Ramakrishna M, Hangland HK, Lilleng PK, Nik-Zainal S, McLaren S, Butler A, Martin S, Glodzik D, Menzies A, Raine K, Hinton J, Jones D, Mudie LJ, Jiang B, Vincent D, Greene-Colozzi A, Adnet PY, Fatima A, Maeteus M, Ignatiadis $\mathrm{M}$, Stratton MR, Sotiriun $\mathrm{C}$, Richardson $\mathrm{AL}$, Lonning PE, Wedge DC, Campbell PJ (2015) Subclonal diversification of primary breast cancer revealed by multiregion sequencing. Nat Med 21(7): 751-759.

Yerushalmi R, Woods R, Kennecke H, Speers C, Knowling M, Gelmon K (2010) Patterns of relapse in breast cancer: changing patterns over time. Breast Cancer Res Treat 120(3): 753.

Yonemori K, Tsuta K, Shimizu C, Hatanaka Y, Hashizume K, Ono M, Nakanishi Y, Hasegawa T, Miyakita Y, Narita Y, Shibui S, Fujiwara Y (2008) Immunohistochemical profiles of brain metastases from breast cancer. J Neurooncol 90(2): 223-228.

Yuan Y, Qin L, Liu D, Wu RC, Mussi P, Zhou S, Songyang Z, Xu J (2007) Genetic screening reveals an essential role of p27kip1 in restriction of breast cancer progression. Cancer Res 67(17): 8032-8042.

This work is published under the standard license to publish agreement. After 12 months the work will become freely available and the license terms will switch to a Creative Commons AttributionNonCommercial-Share Alike 4.0 Unported License. 